\title{
Section Location Technology Based on Minkowski Distance of Three-phase Asymmetric Current Components
}

\author{
Shi Kejian ${ }^{1 *}$, Zhu Yidong ${ }^{1}$, Zheng Zimo ${ }^{2}$, Zhang Xinyu ${ }^{1}$, Tian Ye ${ }^{1}, X$ Weili², Wang Shili ${ }^{2}$ \\ ${ }^{1}$ State Grid LiaoNing Electric Power Research Institute, Liaoning, Shenyang 110000, China. \\ ${ }^{2}$ Beijing DHHB Power Science and Technology Co.,Ltd, Haidian District, Beijing 100085, China.
}

\begin{abstract}
Fault components in the fault path and the non-fault path differ due to the unbalanced distribution of positive, negative and zero-sequence components in the line in the case of a single-phase earth fault in the power distribution network. Therefore, this paper proposes an improved fault section location algorithm based on phase current, which obtains the fault component current by the subtraction of currents before and after the fault and the fundamental wave amplitude of the corresponding current through Fast Fourier Transform (FFT). Meanwhile, considering that the fault section location cannot be completed accurately with the amplitude relationship alone, the Minkowski distance calculation formula is introduced to strengthen the difference between the fault path and the non-fault path, and the relationship between the calculation results of different sections and the threshold is compared by threshold setting to complete the section location. This paper proposes the specific fault section location process and criteria and verifies the feasibility of the algorithm through simulation experiment.
\end{abstract}

\section{Introduction}

The safe and reliable operation of the distribution network as a link between users and the power system directly concerns the production and living quality of people ${ }^{[1-2]}$. In recent years, the capacitance current of the system has increased due to the increasing proportion of electrical and electronic equipment in the distribution network, changing the neutral grounding mode of the distribution network gradually from the isolated neutral mode to the mode of grounding via arc suppression coil. With the continuous development of social economy, the expansion of coverage area of the distribution network and the complication of its topological structure, the reason above results in the poor application effect of traditional distribution network fault location technology, which greatly reduces the power supply reliability of the distribution network ${ }^{[3-5]}$.

Location methods can be divided into two categories based on the judgment signal of the distribution network fault location technology: first, algorithms completing fault location based on signals of the distribution network line itself ${ }^{[6-7]}$; second, algorithms completing fault location based on external injected signals ${ }^{[8-10]}$. Due to the continuous development of artificial intelligence technology, some location technologies have adopted the idea or algorithm of artificial intelligence technology, which further improves the reliability of the algorithm ${ }^{[11-14]}$. However, the algorithms above still have some problems. Fault location algorithms based on the signal of the line itself mostly use the zero-sequence signal in the line to complete fault judgment. However, zero-sequence signals that can meet the location requirements of algorithms cannot be collected due to the old equipment in the distribution network in some areas or the lack of zero-sequence current or voltage transformers in ring main units or branch boxes of cables, thus reducing the adaptability of the algorithm and making the practical application of fault location algorithms based on the signal of the line itself limited. For fault location algorithms based on external input and output signals, it is required to install additional fault location signal injection and detection devices in distribution network lines. Due to the complex structure and wide coverage of the distribution network, a large number of such devices need to be installed in order to meet the reliability requirement of algorithms, which will greatly affect the efficiency of the algorithm. Most fault location technologies based on intelligent algorithms require a lot of calculations, which will reduce the speed of algorithms. Meanwhile, most of the above algorithms need to upload the signals collected to the master station to complete fault location, which will depend heavily on the communication system. When the communication system is interfered or failed, the algorithm will fail.

To solve the above problems, researchers have proposed a location algorithm that uses the phase current as the fault criterion signal. There is a lot of fault information in the phase current after occurrence of a single-phase earth fault, which can fully support the algorithm to complete fault location. At the same time, the algorithm based on the phase current which is a signal easier to be obtained than the zero-sequence signal,

\footnotetext{
* Corresponding author's e-mail: kejian1986@163.com
} 
is more adaptable. Literature [15] proposed that the fault location could be completed as the variation of phase currents differed in the fault path and the non-fault path in the case of a single-phase earth fault of the distribution network. However, the fault component current is much smaller than the load current in the distribution network, making the algorithm easy to make an error during judgment of the phase current variation and resulting in the failure to guarantee its reliability. Literature [16] proposed that the fault location could be completed as the direction of the sudden change of the fault phase was opposite to that of the non-fault phase in the fault path while the three phases had the same direction of sudden changes in the non-fault path at the moment of the fault. However, considering the complicated earthing conditions in the distribution network, the current transient process easily becomes inconspicuous in the case of high-resistance earthing, making the algorithm unable to locate the sudden change direction accurately and resulting in wrong results of judgment.

This paper puts forward a section location algorithm based on the Minkowski distance of three-phase asymmetric current components. The algorithm first subtracts the currents before and after the fault to extract the fault component current in the line, reducing the influence of the load current on the fault component current. Second, it uses FFT to obtain the fundamental frequency amplitude of the signal and obtains the calculation results of different lines through the Minkowski distance formula to enhance the difference between the non-fault path and the fault path. The fault section location is completed based on the relationship between the calculation results of lines and the adaptive threshold set. The algorithm only uses the phase current as the criterion signal, avoiding the poor adaptability of algorithms caused by the failure to collect the zerosequence signal. Meanwhile, it can complete the in-situ judgment of lines based on the adaptive threshold or upload the signal to the master station to identify the fault section, thereby reducing dependence on the communication system.

\section{Analysis of fault component current}

Taking the system with neutral point grounded via arc suppression coil as an example, this paper analyzes the change process of the phase current with the symmetrical component method. The distribution network system is shown in Figure 1:

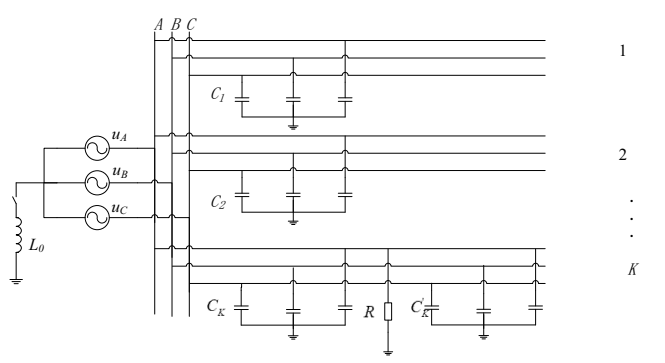

Figure 1: System structure diagram
$\mathrm{u}_{\mathrm{A}}, \mathrm{u}_{\mathrm{B}}$ and $\mathrm{u}_{\mathrm{C}}$ are power supply voltages. $\mathrm{Cj}(\mathrm{j}=1$, $2 \ldots \mathrm{K})$ is the ground capacitance of each line. The fault occurs in phase A of line K. $C_{K}^{\prime}$ is the ground capacitance downstream of the fault point.

Positive, negative and zero-sequence voltages can be input equivalently at the earthing point of the system based on the symmetrical component method, as shown in Figure 2:

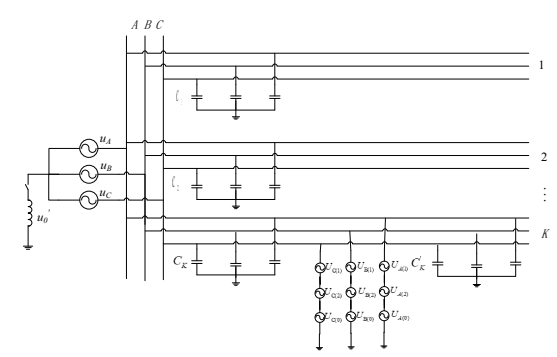

Figure 2: System structure diagram of symmetrical component method

$$
\dot{U}_{\mathrm{A}(1)}, \quad \dot{U}_{\mathrm{B}(1)} \text { and } \dot{U}_{\mathrm{C}(1)} \text { are positive sequence }
$$

voltages of phases $\mathrm{A}, \mathrm{B}$ and $\mathrm{C}$ at the fault point; $\dot{U}_{\mathrm{A}(2)}$, $\dot{U}_{\mathrm{B}(2)}$ and $\dot{U}_{\mathrm{C}(2)}$ are negative sequence voltages of phases $\mathrm{A}, \mathrm{B}$ and $\mathrm{C}$ at the fault point; $\mid \dot{U}_{\mathrm{A}(0)}, \dot{U}_{\mathrm{B}(0) \text { and }}$ $\dot{U}_{\mathrm{C}(0)}$ are zero-sequence voltages of phases $\mathrm{A}, \mathrm{B}$ and $\mathrm{C}$ at the fault point.

After a fault occurs, the current in the system is generated by the combined action of the power supply voltage and positive, negative and zero-sequence voltages. According to the circuit superposition theorem, the phase current $\dot{I}_{F}$ on the line after the fault is equivalent to the sum of the load current $\dot{I}_{d}$ generated by the power supply of the generator and the fault component current $\dot{I}_{f}$ generated by positive, negative and zero-sequence voltages, as shown in Formula 1.

$$
\dot{I}_{F}=\dot{I}_{d}+\dot{I}_{f}
$$

Considering that the generator power is basically unchanged before and after the fault, the load current on the line after the fault is approximately equal to that before the fault, and the load current before the fault is the line phase current.

$$
\dot{I}_{d}^{\prime}=\dot{I}_{d}
$$

On this basis, the fault component current $\dot{I}_{f}$ after the fault can be obtained by subtraction of the phase current $\dot{I}_{d}^{\prime}$ after the fault from that before the fault.

$$
\dot{I}_{f}=\dot{I}_{F}-\dot{I}_{d}^{\prime}
$$

Most of the positive and negative sequence currents are centered on the fault path since the positive and negative sequence currents in the fault component only form a loop between the power source and the fault point. 
There will be a zero-sequence current in each line of the system since a shunt current of the zero-sequence current on the fault line will be formed between the ground capacitance on each line and the earth fault line. The zero-sequence equivalent circuit is as follows:

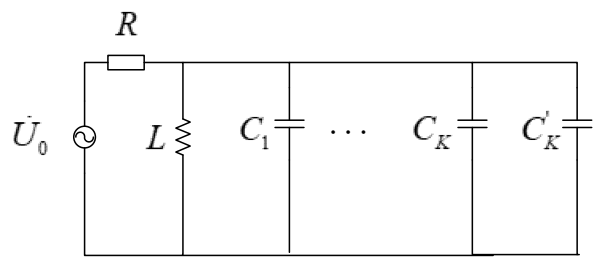

Figure 3: Zero sequence current sequence network diagram

$\dot{U}_{0}$ is the zero-sequence voltage; $C_{j}$ is the ground capacitance value of each line $(\mathrm{j}=1,2 \ldots \mathrm{K}) ; L_{\text {is }}$ the inductance value of the arc suppression coil; $C_{K}$ is the ground capacitance value of the line upstream of the fault point; $C_{K}^{\prime}$ is the ground capacitance value of the line downstream of the fault point; $R$ is the ground resistance.

According to Figure 3, the zero-sequence current is shunted at the fault point and flows to the lines upstream and downstream of the fault point respectively. The zero-sequence current in the line upstream of the fault point at the busbar is shunted and flows to the non-fault lines respectively. For ease of description, the line upstream of the fault point is called the fault path, and the line downstream of the fault point and the normal line are called the non-fault paths. $\gamma_{i}$ is the shunt coefficient. The shunt coefficient $\gamma_{i}$ of the zerosequence current on line $\mathrm{i}$ is:

$$
\gamma_{i}=\frac{j \omega L_{0}}{\alpha \cdot\left(j \omega L_{0} \sum_{m=1}^{L} C_{m}+1\right)}
$$

$C_{i}$ is the ground capacitance on line $\mathrm{i}(\mathrm{i}=1,2 \ldots \mathrm{L})$; $\alpha$ is the impedance value corresponding to the ground capacitance or arc suppression coil on a certain line.

Since the zero-sequence current on the fault path is the sum of zero-sequence currents excluding those downstream of the fault point, the shunt coefficient is:

$$
\gamma_{K}=1-\frac{j \omega L_{0}}{\frac{1}{j \omega C_{K}^{\prime}} \cdot\left(j \omega L_{0} \sum_{m=1}^{L} C_{m}+1\right)}
$$

\subsection{Analysis of the fault component current on the fault path}

Considering that positive and negative sequence currents in the fault current form a loop between the fault point and the power supply through the busbar and that the zero-sequence current in the fault current forms a loop between the ground capacitance on each line and the fault point through the busbar, the current fault component on the fault path includes positive, negative and zero-sequence currents.

For the sake of generality, assuming that the positive, negative and zero-sequence currents at the fault point obtained by the system with the symmetrical component method are $\dot{J}$ respectively, the three sequence currents $\dot{I}_{1}, \dot{I}_{2}$ and $\dot{I}_{0}$ on the fault path are as follows.

$$
\begin{gathered}
\dot{I}_{1}=\dot{I}_{2}=\dot{J} \\
\dot{I}_{0}=\gamma_{K} \dot{J}
\end{gathered}
$$

$\gamma_{K}$ is the shunt coefficient of the zero-sequence current on the fault path, and the direction factor is $a=e^{j 120^{\circ}}$. Therefore, the fault components $\dot{I}_{f A^{\prime}}, \dot{I}_{f B}$ and $\dot{I}_{f C}$ of each phase on the fault line are as follows:

$$
\begin{gathered}
\dot{I}_{f A}=\dot{I}_{A 1}+\dot{I}_{A 2}+\dot{I}_{A 0}=\dot{J}+\dot{J}+\gamma_{K} \dot{J}=\left(2+\gamma_{K}\right) \cdot \dot{J} \\
\dot{I}_{f B}=\dot{I}_{B 1}+\dot{I}_{B 2}+\dot{I}_{B 0}=a \dot{J}+a^{2} \dot{J}+\gamma_{K} \dot{J}=\left(\gamma_{K}-1\right) \cdot \dot{J} \\
\dot{I}_{f C}=\dot{I}_{C 1}+\dot{I}_{C 2}+\dot{I}_{C 0}=a^{2} \dot{J}+a \dot{J}+\gamma_{K} \dot{J}=\left(\gamma_{K}-1\right) \cdot \dot{J}
\end{gathered}
$$

Where, $\dot{I}_{A 1}, \dot{I}_{B 1}$ and $\dot{I}_{C 1}$ are positive sequence components in the three-phase current fault components on the fault path; $\dot{I}_{A 2}, \dot{I}_{B 2}$ and $\dot{I}_{C 2}$ are negative sequence components in the three-phase current fault components on the fault path; $\dot{I}_{A 0}, \dot{I}_{B 0 \text { and }} \dot{I}_{C 0 \text { are }}$ zero-sequence components in the three-phase current fault components on the fault path.

\subsection{Analysis of fault component current on non- fault paths}

Non-fault paths include the normal line and the line downstream of the fault point. Since the positive and negative sequence currents in the fault current only form a loop between the fault point and the power supply through the busbar and do not pass through the non-fault path, and the zero-sequence current in the fault current forms a loop between the ground capacitance on each line and the fault point through the busbar, the current fault component on the non-fault path is mainly composed of zero-sequence currents on its own line.

To ensure the unity, assuming that the positive, negative and zero-sequence currents at the fault point obtained with the symmetrical component method are respectively $\dot{J}$, the positive, negative and zero-sequence currents on the non-fault path are:

$$
\begin{gathered}
\dot{I}_{1}^{\prime}=\dot{I}_{2}^{\prime}=0 \\
\dot{I}_{0}^{\prime}=\gamma_{i} \dot{J}
\end{gathered}
$$


$\gamma_{i}$ is the shunt coefficient of the zero-sequence current on the non-fault path ${ }^{i}$. Fault components $\dot{I}_{f A}^{\prime}$, $\dot{I}_{f B}^{\prime}$ and $\dot{I}_{f C}^{\prime}$ of the three-phase currents on the nonfault path are:

$$
\begin{aligned}
& \dot{I}_{f A}^{\prime}=\dot{I}_{A 1}^{\prime}+\dot{I}_{A 2}^{\prime}+\dot{I}_{A 0}^{\prime}=\gamma_{i} \dot{J} \\
& \dot{I}_{f B}^{\prime}=\dot{I}_{B 1}^{\prime}+\dot{I}_{B 2}^{\prime}+\dot{I}_{B 0}^{\prime}=\gamma_{i} \dot{J} \\
& \dot{I}_{f C}^{\prime}=\dot{I}_{C 1}^{\prime}+\dot{I}_{C 2}^{\prime}+\dot{I}_{C 0}^{\prime}=\gamma_{i} \dot{J}
\end{aligned}
$$

Where, $\dot{I}_{A 1}^{\prime}, \dot{I}_{B 1}^{\prime}$ and $\dot{I}_{C 1}^{\prime}$ are positive sequence components in the three-phase current fault components on the non-fault path; . $\dot{I}_{A 2}^{\prime}, \dot{I}_{B 2}^{\prime}{ }^{\prime}$ and $\dot{I}_{C 2}^{\prime}$ are negative sequence components in the three-phase current fault components on the non-fault path; $\dot{I}_{A 0}^{\prime}, \ddot{I}_{B 0 \text { and }}^{\prime} \dot{I}_{C 0}^{\prime}$ are zero-sequence components in the three-phase current fault components on the non-fault path.

\section{Section location algorithm analysis and flow chart}

\subsection{Analysis of section location algorithm}

According to the analysis above, the fault component current of the fault phase on the fault path is much higher than that of the non-fault phase; the three phases have the same fault component current on the non-fault path. However, considering the complex fault conditions of the distribution network, it is difficult to ensure the reliability of the algorithm based on the amplitude relationship alone. Therefore, it is proposed to strengthen the difference of lines with the Minkowski distance formula which is given below:

$$
D_{i}(x, y)=\left(\sum_{j=1}^{n}\left|x_{j}-y_{j}\right|^{p}\right)^{\frac{1}{p}}
$$

The Minkowski distance formula can reflect the distance between points $\mathrm{x}$ and $\mathrm{y}$. In this paper, we take the fundamental wave amplitude of phase-A, phase-B and phase- $\mathrm{C}$ fault component currents of each line as the coordinate axis to calculate the distance between the point corresponding to the fundamental wave amplitude of each line and the origin of coordinates. Meanwhile, as the parameter $\mathrm{p}$ increases, the calculation result will get closer and closer to the larger value of the three phases. In this way, the parameter $\mathrm{p}$ can be adjusted based on actual conditions of the line to highlight the large difference of the three-phase fault component currents on the fault path and complete the section location.

To meet the requirement that the algorithm can complete in-situ judgment, this paper proposes to set an adaptive threshold $k_{r e l}=e^{\frac{p}{10}} \cdot I_{0}$. Considering that the zero-sequence current of each line is different, the fundamental wave amplitude of the zero-sequence current of the line is used as a parameter during threshold setting so as to improve the adaptability of the algorithm. At the same time, an adaptive parameter $e^{\frac{p}{10}}$ is set in the threshold. When the parameter $p$ in the Minkowski distance calculation formula is adjusted, the threshold can be adjusted adaptively, which improves the reliability of the algorithm.

\subsection{Algorithm flow chart}

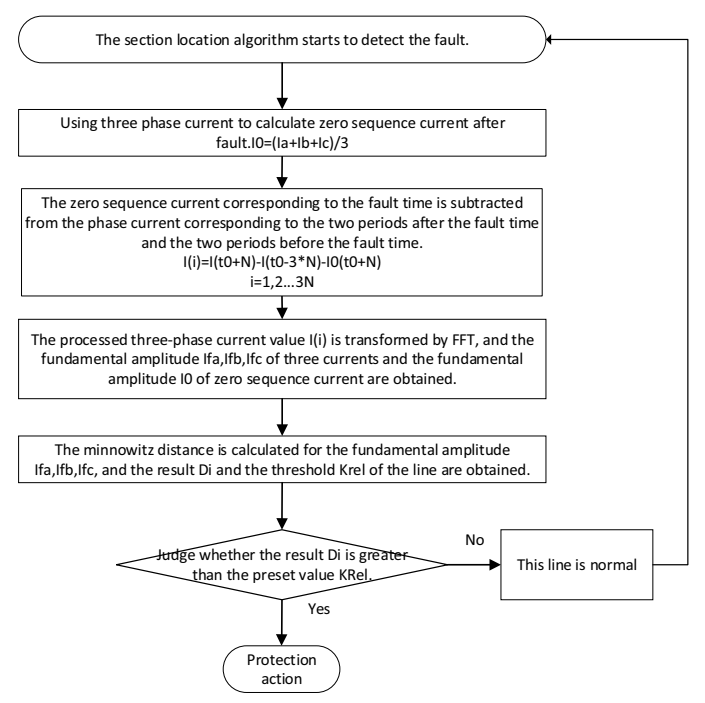

Figure 4: Algorithm flow chart

\section{Test simulation}

This paper sets up a distribution network model with the ATP power system simulation software for simulation experiment. Two grounding modes were used in the experiment - isolated neutral mode and the mode of grounding via arc suppression coil. The fault time was set to $0.0624 \mathrm{~s}$ and the number of sampling points in each cycle was 100 . The experiment was carried out for 25 cycles in total. To facilitate modelling, three outgoing lines were set up in the system, including fault lines and non-fault lines. A single-phase earth fault occurred in the middle section of the fault line. The non-fault lines were divided into no-load lines and load lines. In the experiment, the fault path and the non-fault path were detected. The non-fault paths include the normal line and the line downstream of the fault point.

\subsection{Isolated neutral system test}

The test circuit diagram is as follows: 


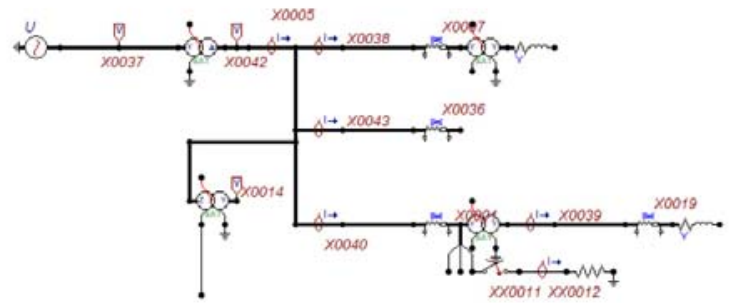

Figure 5: Simulation structure diagram of neutral ungrounded system

The table below shows the fundamental wave amplitude of the three-phase fault component currents and the calculation results after FFT:

Table 1: Calculation results of ungrounded neutral system

\begin{tabular}{|c|c|c|c|c|}
\hline & $\begin{array}{c}\text { Fundame } \\
\text { ntal wave } \\
\text { amplitude } \\
\text { of A- } \\
\text { phase } \\
\text { fault } \\
\text { componen } \\
\text { t current } \\
\text { (A) }\end{array}$ & $\begin{array}{c}\text { Fundame } \\
\text { ntal wave } \\
\text { amplitude } \\
\text { of B- } \\
\text { phase } \\
\text { fault } \\
\text { componen } \\
\text { t current } \\
\text { (A) }\end{array}$ & $\begin{array}{c}\text { Fundame } \\
\text { ntal wave } \\
\text { amplitude } \\
\text { of C- } \\
\text { phase } \\
\text { fault } \\
\text { componen } \\
\text { t current } \\
\text { (A) }\end{array}$ & $\begin{array}{c}\text { Min } \\
\text { distance } \\
\text { calculati } \\
\text { on } \\
\text { results }\end{array}$ \\
\hline $\begin{array}{c}\text { Normal } \\
\text { line }\end{array}$ & 0.6257 & 0.6257 & 0.6257 & 0.7235 \\
\hline $\begin{array}{c}\text { Fault } \\
\text { point } \\
\text { downstre } \\
\text { am line }\end{array}$ & 0.5426 & 0.5426 & 0.5426 & 0.6826 \\
\hline $\begin{array}{c}\text { Fault } \\
\text { path }\end{array}$ & 12.6254 & 3.6289 & 3.6289 & 12.9263 \\
\hline
\end{tabular}

According to the experiment, the calculation result of the fault path is far greater than that of the non-fault path. The algorithm proposed in this paper can locate the single-phase earth fault section of the isolated neutral system.

\subsection{Test of system with neutral point grounded via arc suppression coil}

The test circuit diagram is as follows:

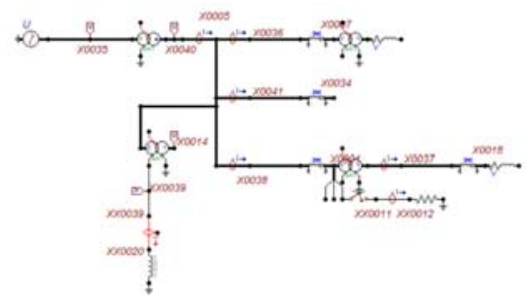

Figure 6: Simulation structure diagram of neutral grounding system through arc suppression coil

The table below shows the fundamental wave amplitude of the three-phase fault component currents and the calculation results after FFT:
Table 2: Calculation results of neutral grounding system through arc suppression coil

\begin{tabular}{|c|c|c|c|c|}
\hline & $\begin{array}{c}\text { Fundame } \\
\text { ntal wave } \\
\text { amplitude } \\
\text { of A- } \\
\text { phase } \\
\text { fault } \\
\text { componen } \\
\text { t current } \\
\text { (A) }\end{array}$ & $\begin{array}{c}\text { Fundame } \\
\text { ntal wave } \\
\text { amplitude } \\
\text { of B- } \\
\text { phase } \\
\text { fault } \\
\text { componen } \\
\text { t current } \\
\text { (A) }\end{array}$ & $\begin{array}{c}\text { Fundame } \\
\text { ntal wave } \\
\text { amplitude } \\
\text { of C- } \\
\text { phase } \\
\text { fault } \\
\text { componen } \\
\text { t current } \\
\text { (A) }\end{array}$ & $\begin{array}{c}\text { Min } \\
\text { distance } \\
\text { calculati } \\
\text { on } \\
\text { results }\end{array}$ \\
\hline $\begin{array}{c}\text { Normal } \\
\text { line }\end{array}$ & 0.4615 & 0.4615 & 0.4615 & 0.5653 \\
\hline $\begin{array}{c}\text { Fault } \\
\text { point } \\
\text { downstre } \\
\text { am line }\end{array}$ & 0.3415 & 0.3415 & 0.3415 & 0.4183 \\
\hline $\begin{array}{c}\text { Fault } \\
\text { path }\end{array}$ & 11.2684 & 2.2616 & 2.2616 & 11.8201 \\
\hline
\end{tabular}

According to the experiment, the calculation result of the fault path is far greater than that of the non-fault path. The algorithm proposed in this paper can locate the single-phase earth fault section of the system with neutral point grounded via arc suppression coil accurately.

\section{Conclusion}

This paper proposes an improved algorithm for singlephase earth fault section location based on phase current. This method obtains the fault component current of the line itself by the subtraction of phase currents before and after the fault, and then obtains the fundamental wave amplitude of the fault component current through Fast Fourier Transform. The results of different lines are calculated by the Minkowski distance calculation formula with parameters pre-designed according to actual system characteristics. The fault section location can be completed by comparison of the relationship between the line calculation results and the threshold. Finally, the feasibility of the algorithm is verified through the simulation experiment.

With the Minkowski distance formula introduced as a criterion, the algorithm can adapt to the characteristics of different regional distribution networks through adjustment of formula parameters and is therefore more adaptable. The threshold setting can allow the algorithm to both transmit the collected signal to the master station for judgment and complete section location in situ, thus realizing its ability of in-situ judgment and reducing the dependence on the communication system.

\section{Fund project:}

Science and technology project of State Grid Liaoning Electric Power Co., Ltd.: Research on rapid disposal and state diagnosis technology of single phase grounding fault of distribution network lines (2020YF-02) 


\section{References}

1. Shi Yankun. Theoretical And Experimental Research On Distribution Automation And Service Realibility. Dalian University of Technology(2006)

2. Wang D, Psaras V, Emhemed A A S, et al. A Novel Fault Let-through Energy based Fault Location for LVDC Distribution Networks. IEEE Transactions on Power Delivery, PP(99):1-1(2020)

3. Liang Rui, Meng Xiangzhen, Zhou Lutian, Peng Nan. Status Quo and Prospect of Distribution Network Fault Location. Electric Power Engineering Technology, 37(06):20-27 (2018)

4. Ramos M J S , Resener M, Bretas A S, et al. Physics-based analytical model for high impedance fault location in distribution networks. Electric Power Systems Research, 188:106577(2020)

5. Khavari S, Dashti R, Shaker H R, et al. High Impedance Fault Detection and Location in Combined Overhead Line and Underground Cable Distribution Networks Equipped with Data Loggers. Energies, 13(2020)

6. Zhuang Wei, Mu Longhua.Active Component of Zero-sequence Current based Single-phase Ground Fault Location in Distribution Grid. JOURNAL OF TONGJI UNIVERSITY (NATURAL SCIENCE), 42(03):468-473(2014)

7. Li Bin, Shu Hongchun. Converter transformer modeling based on additive process and short circuit fault calculation. Electric Power Automation Equipment, 33(04):65-71+94(2013)

8. Du Gang, Liu Feng, Su Gaofeng. Research on technology of grounding fault location combining FTU and "S" signal injecting method in distribution grid. Power System Protection and Control, 38(12):73-76(2010)

9. Bao Xiaofeng, Xiao Kaiwei,Yang Juan, Shao Wu, Tian Qingsheng, Li Bangyuan, Qiao Lianliu. Singlephase Grounding Fault Location Method Based on Active Signal Injection Method.ELECTRIC ENGINEERING (17):135-137(2018)

10. Zhang Huifen, Zhang Fan, Pan Zhencun. Automatic fault locating algorithm based on signal injection method for distribution system. Electric Power Automation Equipment, (06):39-43(2008)

11. Yin Hao, Li Deqiang, Meng Anbo, Wei Minglei, Hong Junjie. Fault location for distribution network based on crisscross optimization algorithm. Power System Protection and Control, 44(21):109114(2016)

12. Rukmani D K, Thangaraj Y, Subramaniam U, et al. A New Approach to Optimal Location and Sizing of DSTATCOM in Radial Distribution Networks Using Bio-Inspired Cuckoo Search Algorithm. Energies, 13(2020)

13. Huang X, Xie Z, Huang X . Fault Location of Distribution Network Base on Improved Cuckoo Search Algorithm[J]. IEEE Access, 8:22722283(2020)
14. Guo Wenhua. Current Phase Comparison Method for Fault Location of Distribution Network. Techniques of Automation \& Applications, 38(10):107-110(2019)

15. Berggren J, Hammarson L. Novel method for selective detection of earth faults in high impedance grounded distribution networks. In: International Conference \& Exhibition on Electricity Distribution. IET. Lyon. pp. 57-59(2010)

16. Chang Zhongxue, Song Guobing, Huang Wei, Guo Shanghua, Zhang Wei. Phase Voltage and Current Fault Components Based Fault Segment Location Method Under Single-Phase Earth Fault in Distribution Network [J]. Power System Technology, 41(07):2363-2370(2017) 